\title{
American College of Surgeons Oncology Group
}

National Cancer Institute

\section{Source}

National Cancer Institute. American College of Surgeons Oncology Group. NCI

Thesaurus. Code C19712.

A cooperative group sponsored by the $\mathrm{NCl}$ whose primary goal is to evaluate surgical therapies in the management of patients with malignant solid tumors. The ACOSOG (Durham, NC) includes general and specialty surgeons, representatives of related oncologic disciplines and allied health professionals in academic medical centers and community practices throughout the US and foreign countries. The group is composed of the Administrative Coordinating Center and the Statistics and Data Coordinating. Both groups are based at the Duke Clinical Research Institute. 